Джафарова 3.К. Оценка налогового потенциала региона и формирование налоговых доходов Республики Дагестан

УДК 336.221

DOI: $10.21779 / 2500-1930-2020-35-4-90-96$

\title{
3.К. Дюкафарова
}

\section{Оценка налогового потенциала региона и формирование налоговых доходов Республики Дагестан}

Дагестанский государственный университет; Россия, 367000, 2. Махачкала, ул. М. Гаджиева,43a; dazamat67@mail.ru

Развитие любого государства мира, его экономики невозможно без эффективно развитой налоговой системы, обеспечивающей бюджеты всех уровней доходами от налоговых поступлений. Однако в основе любой стабильно развивающейся налоговой системы лежит налоговая политика государства, определяемая посредством и при помощи налогового потенциала государства, его регионов на основе методов налогового планирования и прогнозирования.

Ключевые слова: налоговый потенциал, налоговое прогнозирование, налоговое планирование, налоговая политика, налогообложение.

Основой деятельности любого государства является создание стабильно развивающейся экономики в стране. Для непосредственного осуществления своих функций государству необходимо располагать собственными финансовыми средствами и определить собственную налоговую политику. Налоговая политика как косвенный метод государственного регулирования более гибко воспринимается экономикой и поэтому более широко применяется в рыночных системах, чем методы прямого государственного регулирования.

Гармонизация налоговой системы связана с поиском оптимального соотношения между стимулирующей и фискальной ролью налогов. В этом случае можно ожидать более справедливого распределения налогового бремени, перехода к оптимальным налоговым ставкам и упрощения налоговой системы в стране [6].

Региональные бюджеты могут рассчитывать на еще большие поступления от налоговых поступлений, если пересмотреть систему льгот, предусмотренных федеральным законодательством по налогу на имущество организаций в отношении объектов коммунального назначения, магистральных трубопроводов, линий электропередач, что приводит к значительным потерям доходов местных бюджетов. Альтернативой пересмотру данной системы льгот может стать компенсация из федерального бюджета недополученной доходной части местного и регионального бюджетов.

Для регионов, достигших высоких показателей налогового потенциала, можно сохранить или даже увеличить доли федеральных налогов, поступающих в бюджет субъекта, что может быть реализовано за счет увеличения ставки зачисления акцизов [7].

Таким образом, можно сделать вывод, что существующие несовершенства механизма распределения субсидий на выравнивание бюджетной обеспеченности могут негативно повлиять на величину налогового потенциала более развитых регионов с высоким уровнем собственных доходов, поскольку эти субъекты нуждаются в существен- 
Джафарова 3.К. Оценка налогового потенциала региона и формирование налоговых доходов Республики Дагестан

ном финансировании. Налоговый потенциал страны складывается из налоговых потенциалов регионов по всем видам налогов. Для оценки налогового потенциала региона необходимо проведение достоверного анализа социально-экономического положения, перспектив и тенденций их развития в предстоящий период. Применение достоверных данных в процессе налогового планирования в настоящее время является одной из важных составляющих при оценке налогового потенциала.

По прогнозу на 2021 год удельный вес налогов консолидированного бюджета Республики Дагестан в объеме ВВП составит 4,5 \%, что в 2,2 раза ниже, чем по Ставропольскому краю (9,9\%). Валовый региональный продукт по Республике Дагестан и Ставропольскому краю практически одинаковы (РД - 716,3 млрд рублей; СК - 723,0 млрд рублей).

При этом объем налогов в валовой региональный продукт по законопроекту на 2021 год планируется в размере 4,5 \%, что на уровне оценки 2020 года или со снижением к отчету за 2019 год на 2 процентных пункта (валовой региональный продукт за 2016 год - 611,1 млрд рублей, налоги консолидированного бюджета - 33,5 млрд рублей).

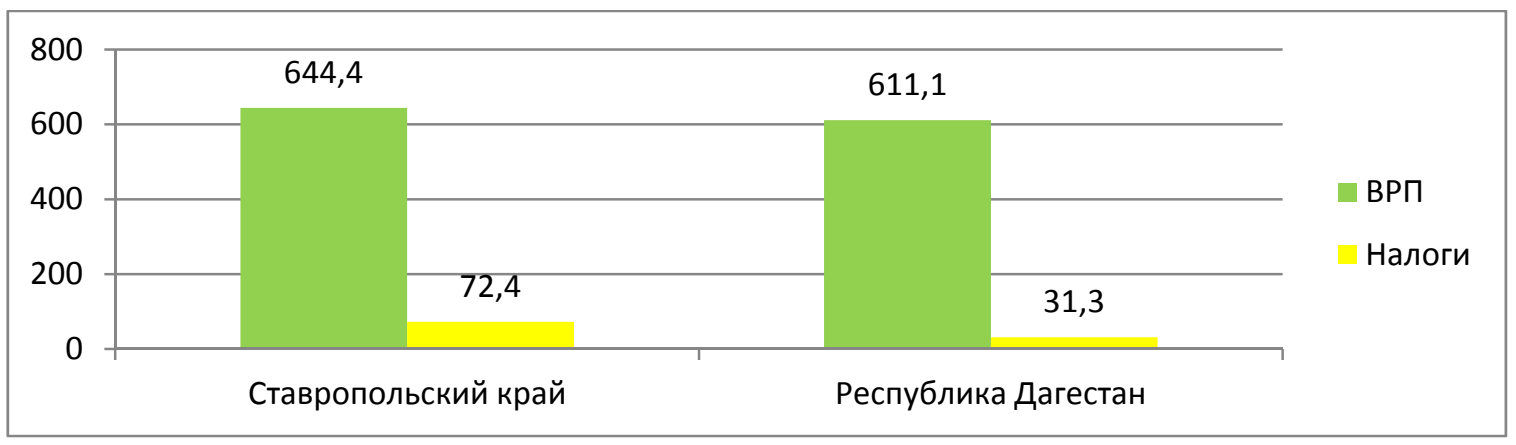

Рис. 1. Валовой региональный продукт РД и Ставрополья по итогам 2019 г.

Источник: ФНС РФ https://www.nalog.ru

По итогам данных ФНС РФ по РД и Ставропольскому краю можно сделать определенные выводы. Показатель ВРП по РД ниже аналогичного показателя по Ставрополью в 5,4 раза. В то же время показатели РД по сельхозпродукции ниже в 1,7 раза, а по экономической деятельности «сельское хозяйство, охота и оказание услуг в этих сферах» (по отчету за 2019 год - 109 754,0 тыс. руб.) в 42 раза ниже, чем в Ставрополье [1].

Однако РД опережает субъекты СКФО по обороту розничной торговли. В то же время опережающий рост указанных показателей не находит соответствующего отражения в поступлении налоговых доходов.

Собственные доходы области составляют 99 \% налоговых отчислений. В 2019 году налоговые поступления в Республике Дагестан составили 33015 млн рублей, из них 8062 млрд поступили в федеральный бюджет, 24926 млн рублей поступило в консолидированный бюджет Республики Дагестан, что составляет 1 млрд рублей. Это больше, чем в 2018 году. В совокупности налоги составляют 85 \% налоговых доходов региона. Рассмотрим поступления по налогам более подробно, собрав данные в виде таблицы 1. 
Джафарова 3.К. Оценка налогового потенциала региона и формирование налоговых доходов Республики Дагестан

Таблица 1. Структура поступлений основных администрируемых доходов по уровням бюджета по РД за 2019 г. (млн руб.)

\begin{tabular}{|l|c|c|c|c|}
\hline \multirow{2}{*}{ Администрируемые доходы } & \multicolumn{2}{|c|}{ в федеральный бюджет } & \multicolumn{2}{|c|}{$\begin{array}{c}\text { консолидированный } \\
\text { бюджет субъекта РФ }\end{array}$} \\
\cline { 2 - 5 } & млн руб. & в \% к соотв. & млн руб. & в \% к соотв. \\
\hline $\begin{array}{l}\text { Всего поступило налоговых } \\
\text { доходов }\end{array}$ & 10432,8 & 113,3 & 34821,7 & 115,8 \\
\hline Налог на прибыль & 410,9 & 120 & 24298,6 & 145,2 \\
\hline НДФЛ & $\mathrm{x}$ & $\mathrm{x}$ & 19311,0 & 118,3 \\
\hline НДС & 190,0 & 87 & $\mathrm{x}$ & $\mathrm{x}$ \\
\hline Акцизы & 555,4 & 43.6 & 2654,0 & 141,8 \\
\hline Налог на имущество физ. лиц & $\mathrm{x}$ & $\mathrm{x}$ & 267,2 & 134,5 \\
\hline $\begin{array}{l}\text { Налог на имущество органи- } \\
\text { заций }\end{array}$ & $\mathrm{x}$ & $\mathrm{x}$ & 3332,5 & 94,7 \\
\hline Транспортный налог & $\mathrm{x}$ & $\mathrm{x}$ & 992,9 & 126,2 \\
\hline Земельный налог & $\mathrm{x}$ & $\mathrm{x}$ & 1227,5 & 103,2 \\
\hline
\end{tabular}

Источник: составлено автором по данным официального сайта ФНС РФ https://www.nalog.ru

Поступление налоговых доходов по данным на 1 января 2020 года в федеральный бюджет - 10 432,8 млн руб., что составило 113,3 \% поступлений прошлого периода (9 217,7 млн руб.). В консолидированный бюджет РД поступило34 821,7 млн руб., что превысило прошлогодний показатель на 15,8 \% (30 066,9 млн руб.).

По налогу на прибыль поступления в 2019 г. увеличились не только по РД, но и по РФ в целом. На $86 \%$ они были сформированы за счет поступлений по основной ставке (в консолидированном бюджете РФ это поступление составило 3,9 трлн рублей, на 7,2 \% больше 2018 года). Основной рост налоговых поступлений по налогу на прибыль организаций по основной ставке обеспечивают промышленность и финансовый сектор в результате роста курса доллара и переоценки валютных обязательств, в том числе рыночных котировок ценных бумаг [8]. По налогу на прибыль организаций при выполнении соглашений о разделе продукции нефти и газа поступления превысили прошлогодние в 1,9 раза за счет увеличения объемов добычи углеводородного сырья и роста стоимости нефти.

Таким образом, общий прирост поступлений налога на прибыль организаций обусловлен на $88 \%$ экономическими факторами, а на $12 \%$ - налоговым администрированием. Недополучение налоговых поступлений выявлено в 2019 г. только по налогу на имущество организаций, поступления по которому снизились на 186,5 млн руб. по сравнению с 2018 годом и темпы его роста составили 94,7\%. В 2018 г. по сравнению с 2017 г. темпы роста этого налога составляли 109, 14 \%. По этому вопросу можно получить разъяснения из публикации на сайте ФНС от 06.03.2020 «О подведении итогов за 2019 г. и намеченных задачах на текущий год» [1].

В отчете руководитель УФНС подчеркнул, что прирост поступлений достигнут по всем основным налогам, кроме налога на имущество организаций: по налогу на прибыль - на 3,9 \%, или 186,5 млн рублей; по акцизам на алкогольную продукцию - на 33,9 \%, или 111,1 млн рублей; по налогу на добычу полезных ископаемых - на 74,5 \%, 
Джафарова 3.К. Оценка налогового потенциала региона и формирование налоговых доходов Республики Дагестан

или - на 15,9 млн рублей; по земельному налогу - на 3,2 \%, или 37,5 млн рублей; по транспортному налогу - на 26,2 \%, или 206,3 млн рублей; по налогу на имущество физических лиц - на 34,5 \%, или 68,6 млн рублей; по единому налогу на вмененный доход - на $0,2 \%$, или на 0,7 млн рублей; по налогу, взимаемому в связи с применением упрощенной системы налогообложения, - на 19,4\%, или 231,1 млн рублей; по единому сельскохозяйственному налогу - на $17,3 \%$, или 8,7 млн рублей; по налогу на доходы физических лиц, без учета разовых поступлений за 2018 год, - в размере 2103,1 млн рублей, а также причитающиеся к уплате в бюджет суммы НДФЛ за 2017 год в размере 342 млн рублей, которые поступили в январе 2018 года, и поступления от крупного плательщика в 2019 году в сумме 4174,4 млн рублей [1].

По налогу на имущество организаций в 2019 году поступило 3332,5 млн рублей, что на 5,3\%, или 186,5 млн рублей, меньше по сравнению с аналогичным периодом прошлого года. На динамику поступлений повлияло изменение налогового законодательства в части предоставления льгот на движимое имущество.

Бюджетные назначения консолидированного бюджета РД за 2019 год, установленные в объеме 26751,7 млн рублей, выполнены на $122 \%$, в бюджет республики дополнительно мобилизовано 5876,3 млн рублей. В том числе бюджетные назначения республиканского бюджета РД, установленные в объеме 22 971,2 млн рублей, исполнены на 125,4 \%; дополнительно в бюджет поступило 4647,3 млн рублей; местный бюджет исполнен на 114,6 \%; дополнительно поступило 1229 млн рублей [1].

Снижение поступлений по налогу на имущество организаций на 5,3 \% (186,5 млн руб.) связано с исключением из объектов налогообложения движимого имущества организаций (Федеральный закон от 03.08.2018 № 302-Ф3). При таких благоприятных показателях налоговых поступлений в консолидированном бюджете есть таблица задолженностей по налогам 4-НМ. Изучив динамику налоговой задолженности по РД (табл. 2), можно сделать выводы о положительной или отрицательной контрольной работе органов ФНС.

Проанализировав данные табл. 2, можно сделать следующие выводы: совокупная задолженность РД в бюджетную систему РФ по федеральным налогам увеличилась на 52,3 \% (1403,6 млн руб.). Из них: задолженность по налогу на прибыль в федеральный налог увеличилась на 18,6 \% (17,6 млн руб.), НДС - на 76,4 \% (на 1259,2 млн руб.), НДПИ - на 9,4 \% (0,9 млн руб.), по остальным федеральным налогам задолженность увеличилась на $18 \%$, или на 79,3 млн руб. Можно однозначно сделать вывод, что контрольная работа по этим видам налогов проводилась не на должном уровне.

Таблица 2. Структура и динамика задолженности консолидированного бюджета Республики Дагестан

\begin{tabular}{|l|c|c|c|c|}
\hline & На & На & \multicolumn{2}{|c|}{ Изменения } \\
\cline { 5 - 6 } \multicolumn{1}{|c|}{ Виды задолженности } & 01.01.2019, & 01.01.2020, & $\%$ & +/-, \\
& в млн руб. & в млн руб. & & в млн руб. \\
\hline $\begin{array}{l}\text { Задолженность в бюджетную систему } \\
\text { РФ федеральных налогов }\end{array}$ & 2681,8 & 4085,4 & 152,3 & 1403,6 \\
\hline Налог на прибыль организаций в ФБ & 94,8 & 112,4 & 118,6 & 17,6 \\
\hline НДС & 1648,2 & 2907,4 & 176,4 & 1259,2 \\
\hline НДПИ & 9,6 & 10,5 & 109,4 & 0,9 \\
\hline Остальные федеральные налоги & 440,9 & 520,2 & 118 & 79,3 \\
\hline $\begin{array}{l}\text { Задолженность в бюджетную систему } \\
\text { РФ региональных налогов }\end{array}$ & 4068,1 & 4441,0 & 109,2 & 372,9 \\
\hline
\end{tabular}


Джафарова 3.К. Оценка налогового потенциала региона и формирование налоговых доходов Республики Дагестан

\begin{tabular}{|l|c|c|c|c|}
\hline $\begin{array}{l}\text { Налог на прибыль в региональный } \\
\text { бюджет }\end{array}$ & 488,3 & 534,8 & 109,5 & 46,5 \\
\hline НДФЛ & 502,1 & 568,7 & 113,3 & 66,6 \\
\hline Налог на имущество & 844,3 & 1199,6 & 142,1 & 355,3 \\
\hline Транспортный налог & 3864,5 & 4460,3 & 115,4 & 596,1 \\
\hline $\begin{array}{l}\text { Задолженность в бюджетную систему } \\
\text { РФ местных налогов }\end{array}$ & 2084,1 & 2107,3 & 101,1 & 23,2 \\
\hline
\end{tabular}

Источник: составлено по данным официального сайта ФНС РФ https://www.nalog.ru

Чуть лучше обстоит дело с налогами, поступающими в региональный и местный бюджеты. Общая задолженность в бюджетную систему РФ региональных налогов составила на 1 января 2020 г. 4441 млн руб., что на 9,2 \% выше аналогичного показателя на 1 января 2019 г., т. е. увеличение задолженности на 372,9 млн руб. Задолженность по налогу на прибыль, поступающему в региональный бюджет, также увеличилась на 9,5 \% (46,5 млн руб.). На 42,1 \% увеличилась задолженность по налогу на имущество и на $15,4 \%$ - по транспортному налогу. По местным налогам задолженность увеличилась незначительно - на $1,1 \%$, что составило 23,2 млн руб. И именно по местным налогам можно говорить о положительной динамике и об эффективной контрольной работе налоговых органов. По всем остальным видам налогов следует подчеркнуть неудовлетворительную работу налоговых органов по проведению контрольной деятельности, камеральных и выездных проверок.

Сумма собранных налогов по НДФЛ на 72 \% состоит из отчислений с бюджетников ( 8 847,2 млн руб.), остальные $28 \%$ (3 379,7 млн руб.) приходится на коммерческие организации. По данным Росстата, численность рабочей силы составляет 1 млн 334 тыс. человек, из которых 1 млн 66 тыс. человек заняты в экономике. Количество физических лиц, получивших доход (по данным налоговой службы), составляет 522 тыс. человек. Разница между этими показателями - 544 тыс. человек.

Прогнозируемый объем фонда оплаты труда в Республике Дагестан в 2,4 раза ниже, чем в Ставропольском крае (221 540,7 млн руб.), а уровень среднемесячной заработной платы (22 547,0 руб.) ниже в 1,2 раза (в Ставропольском крае - 28 014,8 млн руб.), при общей численности занятых в экономике - 1,1 раза (Республика Дагестан 1 203,5 млн тыс. человек, СК - 1 360,2 млн тыс. человек). При этом по уровню денежных доходов на душу населения Республика Дагестан опережает Ставропольский край в 1,3 раза.

Проведенный анализ показывает, что информация, предоставляемая субъектами хозяйствования органам статистики, содержит неполные сведения о фонде оплаты труда. В то же время это говорит о том, что большая часть фонда оплаты труда попрежнему находится в «тени» [9].

На втором месте по доходам бюджета - налог на прибыль организаций. Его доля составляет $17 \%$ от общих налоговых доходов области. Поступления от этого вида налога во многом формируют собственные доходы региона, поскольку 75 \% налоговых отчислений поступает в региональный бюджет. Отчисления по налогу на прибыль условно можно разделить на две категории организаций: «консолидированная группа налогоплательщиков» - крупные организации, действующие на территории Республика Дагестан; все остальные юридические лица, в том числе обособленные подразделения.

Динамика поступлений в региональный бюджет по налогу на прибыль неравномерна. Если в 2015 году выручка была 2,7 млрд рублей, то в 2019 году - 4,2 млрд рублей. 
Джафарова 3.К. Оценка налогового потенциала региона и формирование налоговых доходов Республики Дагестан

Этот прогресс можно связать с выявлением предприятий, завышающих свои затраты с целью снижения налога на прибыль.

В общей доле налоговых поступлений в региональный бюджет налог на имущество организаций составляет $12 \%$. Из-за отсутствия инвентарной стоимости более 150 тысяч объектов недвижимости не платят этот налог. Также есть проблемы с загрузкой данных об объектах недвижимости между Росреестром и Федеральной налоговой службой по Республике Дагестан. В 2018 г. в этом направлении велась работа, что в свою очередь позволило ввести в систему информацию о более чем 143 тысячах объектов недвижимости. Акцизы на алкогольную продукцию играют значительную роль в пополнении областного бюджета, составляя $6 \%$ от общей структуры налоговых доходов бюджета. На наш взгляд, основным резервом пополнения республиканского бюджета Республики Дагестан должно стать принятие эффективных мер по погашению задолженности, недопущению использования налогоплательщиками незаконных механизмов минимизации налоговой базы.

Таким образом, можно сделать вывод, что налоговый потенциал региона составляющая структуры бюджетно-финансового потенциала, то есть максимальная сумма доходов бюджетной системы, потенциально аккумулируемая в виде налогов, сборов и других обязательных платежей от хозяйствующих субъектов данной территории в рамках действующей модели налогообложения на определенный период времени при посредничестве налоговых органов в соответствии с налоговой политикой государства и с учетом экономического развития региона [6].

Налоговые поступления составляют наибольшую долю в структуре налоговых и неналоговых доходов республиканского бюджета Республики Дагестан на 2020 год. Они состоят в основном из федеральных налоговых вычетов (подоходный налог, налог на товары, облагаемые акцизом, корпоративный налог).

Проведенный анализ позволяет сделать вывод о том, что налоговый потенциал должен стать основой для формирования налоговых доходов. Следовательно, необходимо продолжить исследования по изучению процесса формирования налогового потенциала как одной из важнейших составляющих бюджетных возможностей региона.

\section{Литература}

1. Дагестанские налоговики подвели итоги 2019 года и наметили задачи на теку$\begin{array}{llll}\text { щий год. } & \text { Дата } & \text { публикации: } & \\ \end{array}$ https://www.nalog.ru/rn05/news/activities_fts/9656150/

2. Абакарова Х.В. Проблемы и перспективы формирования бюджета РД // Экономические науки. -2015 , июнь.

3. Белогорская А.Н., Сорокина Е.В., Тетерина Н.А. Факторы формирования налоговых доходов региона // Вестник Российского университета кооперации. - 2016. № 4(26). - Режим доступа: https://cyberleninka.ru/article/n/faktory-formirovaniyanalogovyh-dohodov-regiona

4. Билалова И.М., Мамедова А.Р. Оценка эффективности деятельности налоговых органов в РД // Фундаментальные исследования. - 2017. - № 4-2. - С. 320-324. - Режим доступа: http://fundamental-research.ru/ru/article/view?id=41481

5. Горшкова Н.В., Шаманин В.И. Методические подходы к оценке налогового потенциала региона на примере Волгоградской и Ростовской областей // Вестник Волгоградского государственного университета. Сер. 3: Экономика. Экология. - 2016. № 2(35). - Режим доступа: https://cyberleninka.ru/article/n/metodicheskie-podhody-kotsenke-nalogovogo-potentsiala-regiona-na-primere-volgogradskoy-i-rostovskoy-oblastey 
Джафарова 3.К. Оценка налогового потенциала региона и формирование налоговых доходов Республики Дагестан

6. Дёмина Ю.А. Соотношение прямого и косвенного налогообложения в РФ и пути их оптимизации. - Режим доступа: https://scienceforum.ru/2015/article/2015011466

7. Ермакова Ю.С. Налоговый потенциал в системе бюджетного федерализма и стимулирования регионального развития. - Режим доступа: https://cyberleninka.ru/article/n/nalogovyy-potentsial-v-sisteme-byudzhetnogo-federalizma-istimulirovaniya-regionalnogo-razvitiya

8. Мещерякова Л.А. Налоговый потенциал как фактор, определяющий формирование бюджетной политики региона // Региональная экономика: теория и практика. 2018. - № 4 (43). - С. 35-46.

9. Протасова Н.Н. Налоговый потенциал региона: методические и структурные проблемы оценки. http://www.vectoreconomy.ru/images/publications/2017/10/taxes/Protasova.pdf

10. Сапрыкина T.В., Лисиикий Д.С. Оценка налогового потенциала региона в условиях экономических санкций // Фундаментальные исследования. - 2017. - № 8-2. С. 442-447. - Режим доступа: http://fundamental-research.ru/ru/article/view?id=41689

11. Ферзилаева Р.Н. Исчисление налогового потенциала Республики Дагестан // Финансы и кредит / (84) Управление экономическими системами (УЭкС). - 2015. № 11(2).

Поступила в редакиฺюю 25 ноября 2020 г.

UDC 336.221

DOI: $10.21779 / 2500-1930-2020-35-4-90-96$

\section{Assessment of the Tax Potential and Formation of the Tax Revenues in the Republic of Dagestan}

\section{Z.K. Jafarova}

Dagestan State University; Russia, 367000, Makhachkala, M. Gadzhiev st., 43a; dazamat67@mail.ru

The development of any state in the world, its economy is impossible without an effectively developed tax system that provides budgets of all levels with income from tax revenues. However, any steadily developing tax system is based on the tax policy, determined by and with the help of the tax potential of the state and its regions on the basis of tax planning and forecasting methods.

Keywords: tax potential, tax forecasting, tax planning, tax policy, taxation.

Received 25 November, 2020 